\title{
Simulation and Performance Analysis of a Novel LNG Air Vaporizer
}

\section{Coupled with Solar Wall}

\author{
Guo-Hua Shi ${ }^{1, a}$, Dan Li ${ }^{1, b}$, Jia Wang ${ }^{1, c}$, Min Tang ${ }^{1, d}$, and Jin-Rui Zhang',e \\ ${ }^{1}$ Department of Energy and Power Engineering, North China Electric Power University, Baoding, \\ China
}

\author{
${ }^{2}$ Henan Electric Power Survey \& Design Institute, Zhengzhou, China \\ ag.h.shi@ncepu.edu.cn, blidan_ncepu@outlook.com, cjiawangha@outlook.com, \\ dlk_doudoutang@163.com, e17343605@qq.com
}

\begin{abstract}
Keywords: solar wall; CFD numerical simulation; thermal performance; LNG vaporization Abstract. This paper presents a novel LNG air vaporizer that evaporates LNG using hot air generated by a solar wall. The simulation results and an overview of the thermal performance assessment are presented in this work. The simulations were made by use of the CFD software FLUENT to investigate the variation of both air temperature and air velocity in the solar wall. The calculations were also performed for a type YGK-350D AAV to predict the thermal performance of the new air vaporizer under different meteorological conditions and various structure parameters. Compared with a conventional AAV, the heat transfer performance of the novel air vaporizer is increased by 1.82 and 3.03 times on a typical day in summer and winter, respectively.
\end{abstract}

\section{Introduction}

With the speedy development of economy and the acceleration of modernization process, energy and environmental problems have become more and more serious. It is the high time to develop and utilize renewable and clean energies. The solar wall, as a technology of low-temperature solar thermal conversion, is widely applied in building ventilation and heating, and has achieved great effects [1]. However, the structures of solar walls are mostly in flat, which limits the application fields of this technology.

Ambient air-based vaporization (AAV) technology is widely used to vaporize LNG by means of low-grade ambient energy. Unfortunately, ice and frost phenomenon will naturally emerge during the operation of AAV, which worsens its thermal performance. Jiao simulated the formation of frost layer and studied the boiling heat transfer in the pipe of LNG with CFD [2]. Handy Afrianto concluded that the optimization of mass flow was favorable for the vaporization of LNG [3]. In order to lower adverse impact of ice layers on the vaporization capacity of AAV, a lots of measures have been proposed and taken, for example, two parallel groups of AAVs, AAV and water bath vaporizers in series, installing axial fans at the top of AAVs, etc. [4]. But these markedly lead to a significant increase in both initial cost and operation expense, and an enormous operating complexity.

A novel AAV coupled with a solar wall system (AVCSW) [5] is presented in this paper. The corresponding model in Gambit is built. Lastly, we make a contrast between an AAV with solar wall and one without solar wall and analyze the thermal performances. 


\section{Numerical approach and grid design}

As shown in Fig.1 (A), the cold air in surroundings get into the cavity through the small holes and the bottom annular air inlet of solar wall, then absorb the heat from the solar wall, finally, the hot air was sent to AAV for vaporizing LNG with the help of the circular air outlet at the top. In present CFD numerical simulation, we employed the Reynolds Averaged Navier - Stokes equations with the Realizable $\mathrm{k}-\varepsilon$ turbulence closure model, and adopted a first order upwind discretization scheme along with SIMPLE. In Gambit the complicated geometry was split with Hex/Wedge and cooper form. A grid diagram of top circular air inlet and air cavity of solar wall is presented in Fig.1 (B), the grid size of the round tuyere is $0.01 \mathrm{~m}$, the size of the cavity grid is $0.15 \mathrm{~m}$, and the total grid number of AVCSW is about $8 \times 10^{8}$.

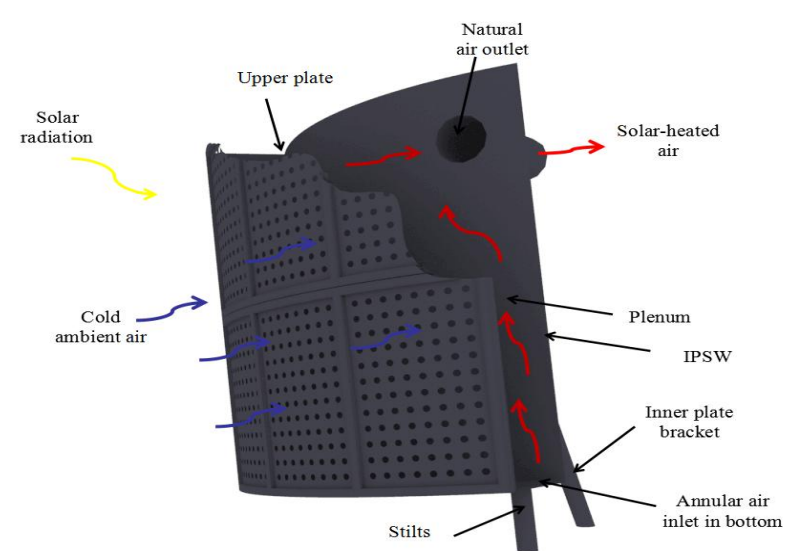

(A)

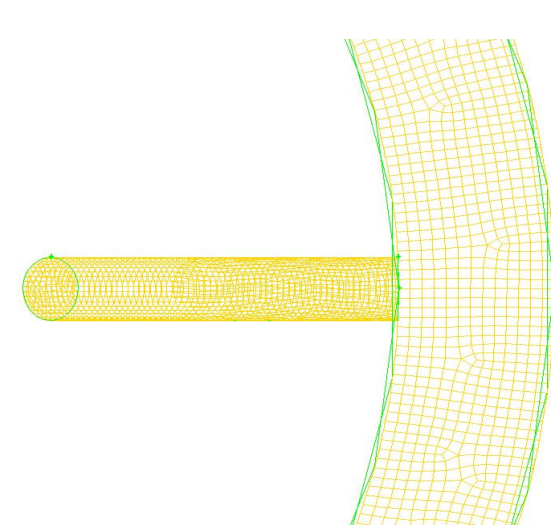

(B)

Fig.1 Structure principle diagram of AVCSW (A) and the mesh model of one-fourth of the air outlet (B).

\section{Boundary conditions and assumptions}

Some assumptions were listed to simply the model: 1) The solar wall is in a steady state; 2) The influence of buoyancy is ignored, and there is no reflow phenomenon; 3) The Boussinque hypothesis is introduced.

DO radiation model was employed, and typical sunny-day weather parameters in Beijing were selected on January $15^{\text {th }}$ in winter and on July $15^{\text {th }}$ in summer, respectively. The wall temperature of solar panel is constant in winter $\left(45^{\circ} \mathrm{C}\right)$ and summer $\left(70^{\circ} \mathrm{C}\right)[6]$. The solar wall is made of by steel with a thickness of 0.002 meters. The air outlet is set to outflow. The other side of the wall is adiabatic boundary. The bottom air inlet and the annular air inlet are set as velocity-inlet, and the speed is $u(\mathrm{~m} / \mathrm{s})$. Turbulence intensity $I$ and water diameter $d$ calculated by the following formulas:

$$
\begin{aligned}
& \mathrm{Re}=\frac{u \times d}{v} \\
& I=0.16 \times \mathrm{Re}^{-1 / 8} \\
& d=d_{2}+d_{1} \\
& \rho=\rho_{0}\left[1-\beta\left(T-T_{0}\right)\right] \\
& \beta=\frac{1}{T}
\end{aligned}
$$


where $d_{1}$ is the diameter of the inner wall $(\mathrm{m}), d_{2}$ is the diameter of the outer wall $(\mathrm{m}), T_{0}$ is the surface temperature of fin tube in $\operatorname{AAV}(\mathrm{K}), \rho$ is the qualitative density of air $\left(\mathrm{kg} / \mathrm{m}^{3}\right), \rho_{0}$ is the initial air density $\left(\mathrm{kg} / \mathrm{m}^{3}\right), \beta$ is the expansion coefficient of air and $T$ is the qualitative temperature $(\mathrm{K})$.

\section{Heat transfer coefficient of AAV alone}

For a conventional AAV without solar wall, the heat transfers between ambient air and the vaporizer by the natural convection. The vertical wall natural convection criterion can be employed to calculate finned tubes with mounted vertically [7]. The calculation of air physical parameters is based on qualitative temperature $T_{\mathrm{m}}$, which can be described as:

$$
\begin{aligned}
& T_{\mathrm{m}}=\frac{T_{0}+T_{a}}{2} \\
& N u=\left\{0.825+\frac{0.387 \mathrm{Re}^{1 / 6}}{\left[1+(0.492 / \mathrm{Pr})^{9 / 16}\right]^{8 / 27}}\right\}^{2} \\
& \operatorname{Re}=G \mathrm{r} \cdot \operatorname{Pr} \\
& G \mathrm{r}=\frac{g \alpha \Delta T L^{3}}{v^{2}} \\
& \operatorname{Pr}=\frac{v}{a} \\
& \alpha=\frac{1}{T_{\mathrm{m}}} \\
& h_{\mathrm{nc}}=\frac{N u \cdot \lambda_{\mathrm{a}}}{L}
\end{aligned}
$$

where $T_{\mathrm{a}}$ is the temperature of ambient air $(\mathrm{K}), \alpha$ is the coefficient of volume expansion $(1 / \mathrm{K}), v$ is the kinematic viscosity $\left(\mathrm{m}^{2} / \mathrm{s}\right), L$ is the set size $(\mathrm{m})$, i.e. the installation height of $\mathrm{AAV}, \triangle T$ is the temperature difference between wall and ambient air, $a$ is the thermal diffusivity $\left(\mathrm{m}^{2} / \mathrm{s}\right), \lambda_{\mathrm{a}}$ is the thermal conductivity of $\operatorname{air}(\mathrm{W} /(\mathrm{m} \cdot \mathrm{K})), h_{\mathrm{nc}}$ is the natural convection heat transfer coefficient $\left(\mathrm{W} /\left(\mathrm{m}^{2} \cdot \mathrm{K}\right)\right)$.

There is a great temperature gradient between the cryogenic fin tube surface and the air around the AAV, which produced the radiation heat between them. Radiative heat transfer coefficient can be written as following:

$$
\begin{aligned}
& h_{\mathrm{nr}}=\frac{\varepsilon_{f} \sigma_{\mathrm{b}}\left(T_{a}^{4}-T_{0}^{4}\right)}{T_{a}-T_{0}} \\
& h_{\mathrm{n}}=h_{\mathrm{nc}}+h_{\mathrm{nr}}
\end{aligned}
$$

where $h_{\mathrm{n}}$ is the compound heat transfer coefficient, $\varepsilon_{\mathrm{f}}$ is the emissivity, 0.98 in this work [8], and $\sigma_{\mathrm{b}}$ is the Stefan-Boltzmann constant with a value of $5.67 \times 10^{-8} \mathrm{~W} /\left(\mathrm{m}^{2} \cdot \mathrm{K}^{4}\right)$.

\section{Heat transfer coefficient of AVCSW}

The heat transfer in AVCSW can be directly into the surface of AAV in the form of jet flow, the convection heat transfer coefficient could be expressed as [9]: 


$$
\begin{aligned}
& \frac{N u}{\operatorname{Pr}^{0.42}}=\left[1+\left(\frac{H / D}{0.6}\right) \sqrt{f}\right]^{-0.05} \frac{\sqrt{f}(1-2.2 \sqrt{f})}{1+0.2(H / D-6) \sqrt{f}} \operatorname{Re}^{2 / 3} \\
& f=\frac{\pi}{4}\left(\frac{D}{S}\right)^{2} \\
& \operatorname{Re}=\frac{u_{1} D}{v} \\
& h_{\mathrm{sc}}=\frac{N u \cdot \lambda_{\mathrm{a}}}{L}
\end{aligned}
$$

where $H$ is the installation height of tuyere $(\mathrm{m}), D$ is the diameter of air outlet $(\mathrm{m}), S$ is the center distance between air outlets, $u_{1}$ is the velocity of air outlet $(\mathrm{m} / \mathrm{s}), f$ is the relative tuyere area, $v$ is the kinematic viscosity $\left(\mathrm{m}^{2} / \mathrm{s}\right), L$ is the set size $(\mathrm{m})$ calculated by the $f, h_{\mathrm{sc}}$ is the convection heat transfer coefficient of AVCSW $\left(\mathrm{W} /\left(\mathrm{m}^{2} \cdot \mathrm{K}\right)\right)$.

When calculating radiative heat transfer coefficient, we assume that the energy of the air outlet is all downward and no leakage. The radiant heat transfer coefficient of AVCSW is derived as:

$$
\begin{aligned}
& h_{s r}=\frac{C_{0}\left[\left(\frac{T_{0}}{100}\right)^{4}-\left(\frac{T_{1}}{100}\right)^{4}\right]}{\left[\frac{1}{\varepsilon_{f}}+\frac{A_{0}}{A_{1}}\left(\frac{1}{\varepsilon_{1}}-1\right)\right]\left(T_{0}-T_{1}\right)} \\
& A_{0}=(\mathrm{a} \times \mathrm{b}+b \times c+a \times c) \times 2-a \times b \\
& A_{1}=\frac{\pi}{4} d_{1}^{2}+\pi d_{1} \times l \\
& h_{\mathrm{s}}=h_{\mathrm{sc}}+h_{s r}
\end{aligned}
$$

where $C_{0}$ is the black body radiation coefficient which value is $5.67 \mathrm{~W} /\left(\mathrm{m}^{2} \cdot \mathrm{K}^{4}\right), \varepsilon_{1}$ is the emissivity of the inner plate which value is $0.8 ; T_{1}$ is the inner wall temperature of the solar wall $(\mathrm{K}), A_{0}$ is the surface area of the AAV $\left(\mathrm{m}^{2}\right), a, b, c$ is the length, width and height of the AAV, respectively (m), $A_{1}$ is the surface area of inner wall $\left(\mathrm{m}^{2}\right), l$ is the height of the solar wall $(\mathrm{m})$ and $h_{\mathrm{s}}$ is the composite convective heat transfer coefficient of air jet flow $\left(\mathrm{W} /\left(\mathrm{m}^{2} \cdot \mathrm{K}\right)\right.$.

\section{The improvement rate of heat transfer in AVCSW}

In order to measure the enhancement of heat transfer performance, we introduce indicators $I H T$, it is defined as:

$$
\begin{aligned}
& I H T_{\text {win }}=\frac{H_{\text {win.s }} \Delta T_{\text {win.s }} A_{0}}{H_{\text {win }} \Delta T_{\text {win }} A_{0}} \\
& \Delta T_{\text {win.s }}=T_{\text {air.outwin }}-T_{0}
\end{aligned}
$$




$$
\begin{aligned}
& I T H_{\text {sum }}=\frac{H_{\text {sum.s }} \Delta T_{\text {sum.s }} A_{0}}{H_{\text {sum }} \Delta T_{\text {sum }} A_{0}} \\
& \Delta T_{\text {sum.s }}=T_{\text {air.outsum }}-T_{0}
\end{aligned}
$$

where $I H T_{\text {win }}$ is the improvement of heat transfer in winter, $I H T_{\text {sum }}$ is the improvement of heat transfer in summer, $H_{\text {win.s }}$ and $H_{\text {sum.s }}$ are composite convective heat transfer coefficients of AVCSW in winter and summer typical day $\left(\mathrm{W} / \mathrm{m}^{2} \cdot \mathrm{K}\right), H_{\text {win }}$ respectively, and $H_{\text {sum }}$ are natural convective heat transfer coefficients of AAV in winter and summer $\left(\mathrm{W} / \mathrm{m}^{2} \cdot \mathrm{K}\right)$, respectively, $\triangle T_{\text {win.s }}$ and $\triangle T_{\text {sum.s }}$ are the temperature differences between inner wall and fin tube of AVCSW in winter and summer $(\mathrm{K})$, respectively, $\triangle T_{\text {win }}$ and $\triangle T_{\text {sum }}$ are the temperature differences between air around AAV and fin tube in winter and summer $(\mathrm{K})$, respectively, $T_{\text {air.outwin }}$ and $T_{\text {air.outsum }}$ is the temperature of the circular air outlet in winter and summer $(\mathrm{K})$, respectively.

\section{Results and discussions}

\section{Thermal performance of circular solar wall}

It can be seen from Fig. 2 (A) (with $u=0.1 \mathrm{~m} / \mathrm{s}, L_{\mathrm{AAI}}=20 \mathrm{~mm}, N u m_{\mathrm{AAI}}$ (number of annular air inlet $=10$ ) that the outlet air temperature will decrease with the increase of cavity distance. The changes of outlet air velocity in winter and summer share the same trend. This is because the air temperature in the cavity is decided by the radiation of plate and the convective heat transfer between walls and air. The smaller the distance of air cavity is, the less the air is. This can influence the thermal boundary layer and the radiation. Therefore, the space between the inner wall and the outer one should not be too large, generally any more than $0.2 \mathrm{~m}$, which is great with previous studies. Fig. 2 (B) (with $L_{\mathrm{AAI}}=20 \mathrm{~mm}, N u m_{\mathrm{AAI}}=10, L_{\text {cavity }}=20 \mathrm{~cm}$ ) shows the air outlet velocity increases quickly and the air temperature declines with the increase of ambient air velocity. High speed in air inlets leads to a high turbulence kinetic, and then results in an enhancement of the heat transfer. More air at higher wind speed is the main reason for the decrement of outlet air temperature with the increment in the ambient air velocity.

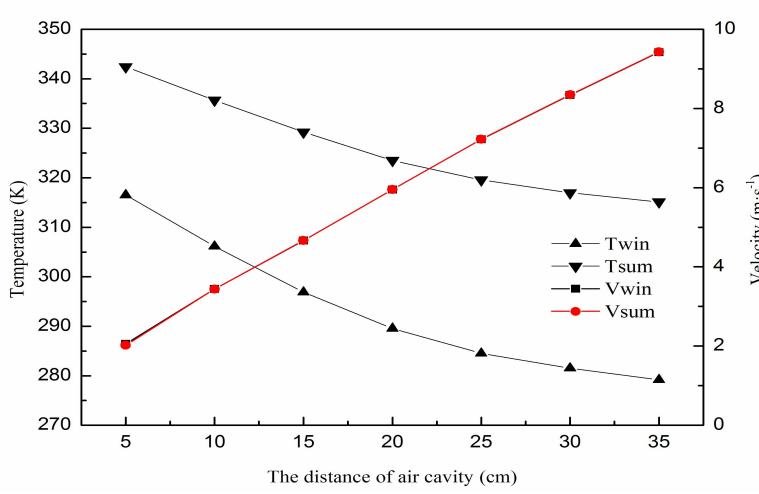

(A)

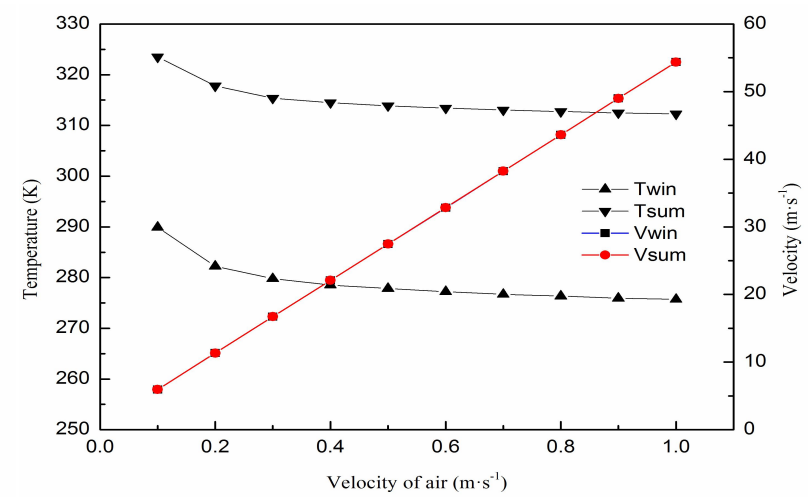

(B)

Fig. 2 The changes of temperature and velocity in air outlets with the distance of air cavity (A) and wind speed of air inlet (B).

\section{Thermal performance of AVCSW}

To validate the accuracy of the coupled heat transfer model developed in this paper, a YGK-350D type AAV was selected to numerically simulate. Table 1 lists some parameters of the AAV. 
Table 1. The structure and geometries of the AAV.

\begin{tabular}{cccccc}
\hline Type & $\begin{array}{c}\text { Rating value } \\
\left(\mathrm{m}^{3} / \mathrm{h}\right)\end{array}$ & $\begin{array}{c}\text { Working pressure } \\
(\mathrm{MPa})\end{array}$ & $\mathrm{a}(\mathrm{mm})$ & $\mathrm{b}(\mathrm{mm})$ & $\mathrm{c}(\mathrm{mm})$ \\
\hline low pressure & 350 & 1.96 & 1885 & 913 & 4450 \\
\hline
\end{tabular}

Table 2. Comparison between the measured data and the simulation results.

\begin{tabular}{ccccc}
\hline & Season & $H_{\text {con }}\left(\mathrm{W} /\left(\mathrm{m}^{2} \cdot \mathrm{k}\right)\right)$ & $H_{\mathrm{r}}\left(\mathrm{W} /\left(\mathrm{m}^{2} \cdot \mathrm{k}\right)\right)$ & $H_{\text {all }}\left(\mathrm{W} /\left(\mathrm{m}^{2} \cdot \mathrm{k}\right)\right)$ \\
\hline \multirow{2}{*}{ AAV } & Winter & 5.67 & 3.22 & 8.89 \\
& Summer & 7.24 & 4.11 & 11.35 \\
\multirow{2}{*}{ AVCSW } & Winter & 28.31 & 3.65 & 31.96 \\
& Summer & 28.93 & 6.87 & 35.8 \\
\hline
\end{tabular}

Table 2 compares the real operating data of the AAV without a solar wall and the simulation results of AVCSW under the same conditions. The natural convection heat transfer coefficient $\left(H_{\text {con }}\right)$ have improved by $399.3 \%$ in winter and $299.6 \%$ in summer, respectively. This is concluded that the solar wall can produce hot air with high speed to enhance the vaporization effects of the AAV. After utilizing the solar wall, the radiant heat transfer also has a significant improvement. The solar wall help the AAV improve its total coefficient of heat transfer by 3.03 times in winter and 1.82 times in summer, respectively.

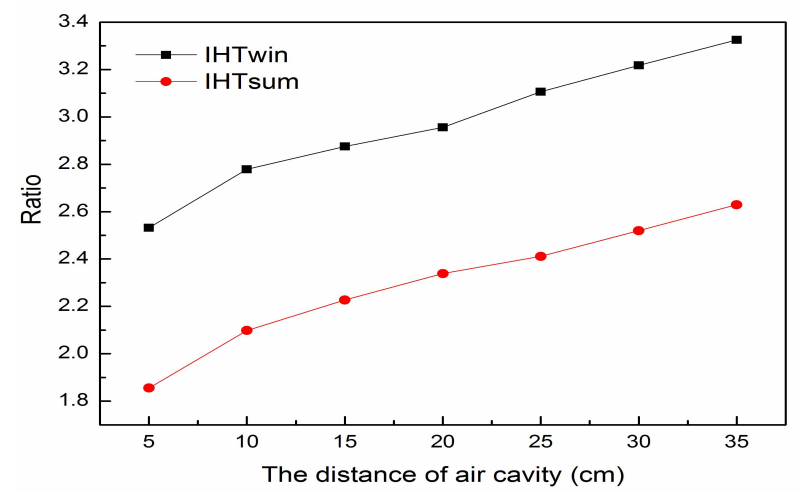

(A)

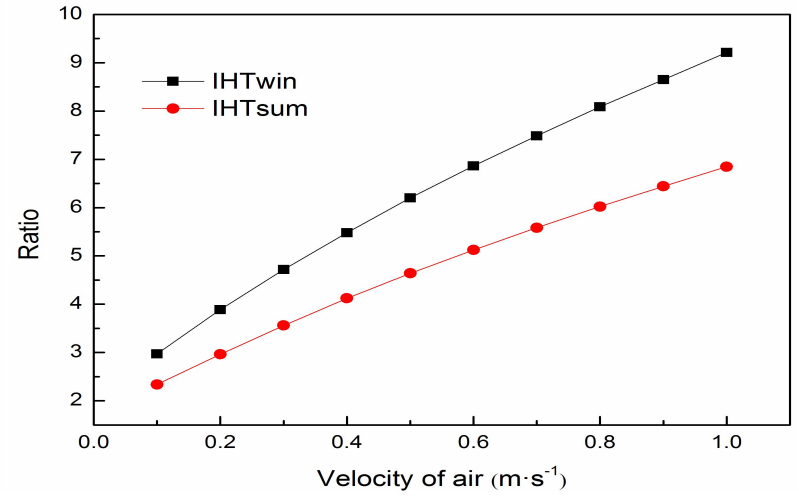

(B)

Fig. 3 The heat transfer coefficient and IHT of the AVCSW with the distance of air cavity (A) and wind speed of air inlet (B)

Fig. 3 (A) indicates the effect of the space between the outer wall and the inner wall on the heat transfer. With the increase of the space, more air is heated by the solar wall before being delivered at higher speed to the AAV. Therefore, the heat transfer coefficient has a remarkable improvement. Because more cold ambient air enters into the cavity under high-space surroundings air, the outlet air temperature decreases. It is a negative effect on the vaporization capacity of the AAV. We can also predict from Fig.3 (A) that an AVCSW is more favorable in winter. Fig. 3 (B) shows the effect of wind speed on the heat transfer of AVCSW. When wind speed intensifies, the vaporization capacity of AAV has an approximately same trend with the convective heat transfer coefficient.

\section{Conclusions}

A CFD-based coupled numerical model of an AVCSW was presented and used to investigate its thermal performances. After a comparison with the practical operating data of an $\mathrm{AAV}$, it is concluded that the AVCSW has an outstanding vaporization performance no matter in summer or 
winter. Hence, the solar wall will help the AAV obtain good vaporization ability and inhibit the formation of ice and frost on the surface. Certainly, higher wind speed and a proper space of air cavity will contribute to a better heat transfer performance.

\section{Acknowledgements}

The authors greatly acknowledge the financial support from the Natural Science Foundation of Hebei Province (E2016502027), the Scientific Research Project of Education Department of Hebei Province (Z2015119) and the Fundamental Research Funds for the Central Universities (2017MS124).

\section{References}

[1] T.T. Zhang, Y.F. Tan, et al. A glazed transpired solar wall system for improving indoor environment of rural buildings in northeast China. Building and Environment, Vol. 98 (2016), p. 158-179.

[2] S.S. Liu, W.L. Jiao, L.M. Ren, et al. Dynamic heat transfer analysis of liquefied natural gas ambient air vaporizer under frost conditions. Applied Thermal Engineering, Vol. 110 (2017), p. 999-1006.

[3] A. Handry, T. Riyad, Munkhbayar. A numerical investigation on LNG flow and heat transfer characteristic in heat exchanger. International Journal of Heat and Mass Transfer, Vol. 68 (2014), p. 110-118.

[4] D.L. Luo. Study on formation and treatment of cold fog in LNG gasifier. Guangzhou: South China University of Technology (2013).

[5] G.H. Shi, D. Li, S.N. Tian. Chinese patent: CN205447259U (2016).

[6] J. Huang. Thermal characteristics and application of porous solar wall. Baotou: Inner Mongolia University of Science and Technology (2012).

[7] X.M. Zhang, Z.X. Ren, F.M. Mei. Heat transfer theory, 5rd ed. Beijing: China Construction Industry Press (2007).

[8] P.X. Hou. Experimental study and theoretical analysis of frost growth. Nanjing: Southeast University (2006).

[9] C.F. Ma, W.Z. Gu, Y.M. Zhang, J.R. Shen. Heat transfer enhancement. Beijing: Science Press (1990). 